\title{
Carbon dioxide versus room air for colonoscopy in deeply sedated pediatric patients: a randomized controlled trial
}

\section{다 (1) $\odot$}

\author{
Authors \\ Institutions \\ 1 Department of Pediatrics and Adolescent Medicine, \\ University Medical Center Ulm, Ulm, Germany \\ 2 Institute of Epidemiology and Medical Biometry, Ulm \\ University, Ulm, Germany.
}

Andrea Kresz ${ }^{1}$, Benjamin Mayer ${ }^{2}$, Maria Zernickel' ${ }^{1}$, Carsten Posovszky ${ }^{1}$ submitted 7.6.2017

accepted after revision $\quad 24.9 .2018$

\section{Bibliography}

DOI https://doi.org/10.1055/a-0806-7060 |

Endoscopy International Open 2019; 07: E290-E297

(C) Georg Thieme Verlag KG Stuttgart · New York

ISSN 2364-3722

Corresponding author

Carsten Posovszky, MD, Pediatric Gastroenterology and

Nutrition, Department of Pediatrics and Adolescent

Medicine, University Medical Center Ulm, Eythstr. 24,

89075 Ulm, Germany

Fax: +0731-50057334

carsten.posovszky@uniklinik-ulm.de

\section{ABSTRACT}

Background and study aims Use of carbon dioxide $\left(\mathrm{CO}_{2}\right)$ instead of room air (RA) during colonoscopy in adults revealed significantly less flatulence and abdominal pain in several studies. The objectives of this study were to investi- gate the effects of $\mathrm{CO}_{2}$ usage on post-interventional pain, abdominal discomfort, abdominal girth, $\mathrm{pCO}_{2}$ levels, and narcotic requirement in deeply sedated pediatric patients. Patients and methods A total of 97 children and adolescents aged 4 years to 17 years undergoing colonoscopy were randomized to $\mathrm{RA}$ or $\mathrm{CO}_{2}$ in a prospective, randomized, controlled trial. Age-appropriate pain scales assessed abdominal pain as primary outcome. In addition, abdominal girth, abdominal bloating, transcutaneous $\mathrm{pCO}_{2}$, narcotic requirement to achieve deeply sedation, and post-procedural analgesic demand was analyzed in 73 patients.

Results Overall, significantly fewer patients reported bloating in the $\mathrm{CO}_{2}$ group $(P=0.0012)$. However, we observed only a trend to lower post-interventional pain $(P=$ 0.15 ) and a lower pain score. There was no significant difference in transcutaneous $\mathrm{pCO}_{2}$ level and no adverse events occurred. Although there was no difference in the dosage of propofol and midazolam, we observed a significant increased necessity for use of synthetic opioids in the RA group to achieve optimal examination conditions $(P=$ 0.023).

Conclusions The benefits using $\mathrm{CO}_{2}$ in colonoscopy of deeply sedated children predominate. In particular, $\mathrm{CO}_{2}$ insufflation may allow a less painful post-interventional time and it significantly reduces abdominal bloating. Moreover, with $\mathrm{CO}_{2}$, significantly less additional opioids were used. Thus, $\mathrm{CO}_{2}$ insufflation can be considered as safe in deeply sedated patients as there was no relevant pulmonary $\mathrm{CO}_{2}$ retention observed. (DRKS00013914)

\section{Introduction}

Intestinal distention is required to achieve optimal visualization of the bowel during colonoscopy. Therefore, up to 19.81 of room air (RA) is insufflated. The intestinal resorption rate of RA is poor and leads to post-procedural bowel distension [1, 2], thereby causing abdominal bloating and post-interventional-related pain and discomfort for up to 48 hours.

Carbon dioxide $\left(\mathrm{CO}_{2}\right)$ is absorbed 150 times faster from the intestinal lumen into the blood stream than RA. Accordingly, use of $\mathrm{CO}_{2}$ instead of RA during colonoscopy revealed less flatulence and abdominal pain in adults [1-9]. A meta-analysis con- firmed the clinical advantages of $\mathrm{CO}_{2}$ insufflation in respect to pain [10]. In addition, due to the high pulmonary elimination rate, there is no risk of pulmonary $\mathrm{CO}_{2}$ retention $[4,6,8,11,12]$.

Colonoscopy is a routine diagnostic and therapeutic intervention in children. In particular, children receive more air in relation to their body height during colonoscopy than do adults. Thus, the benefits of $\mathrm{CO}_{2}$ insufflation for children should be even greater by decreasing abdominal discomfort and reducing complications associated with excessive bowel distension such as ischemia and perforation. We performed a randomized, controlled trial (RCT) to investigate the advantage of $\mathrm{CO}_{2}$ insufflation compared to RA during colonoscopy in deeply sedated 
children and adolescents as there were no data from pediatric RCTs available at that time. Our primary aim was to determine whether $\mathrm{CO}_{2}$ reduces post-procedural pain. The secondary aims were to assess abdominal distension, bloating, pulmonary $\mathrm{CO}_{2}$ retention, and the impact on use of anesthetics in pediatric patients.

\section{Patients and methods}

\section{Patient enrollment and randomization}

The study was a prospective RCT (DRKS00013914) approved by the institutional review board of Ulm University (No304/12) and was conducted according to the current version of the Declaration of Helsinki Ethical Principles for medical research [13]. Children aged 4 to 17 years who underwent colonoscopy at the Department of Pediatrics and Adolescent Medicine of the University Medical Centre Ulm, Germany, were consecutively enrolled between January 2014 and December 2016. Informed written consent was obtained from the legal guardian and study information was handed out to all participants and parents before the study. Patients with cardiac problems, acute pulmonary infections and chronic lung disease, mental disability, pregnancy, and patients with known allergy of propofol and midazolam were excluded from the study as were patients with colon resection or stomata. Patients were recruited for the study by the endoscopist and randomly assigned to receive insufflation with either $\mathrm{CO}_{2}$ or RA during their colonoscopy by envelope method. Allocation bias was minimized in both arms by using different sealed envelopes for girls and boys, and for age groups 4 to 12 year and 13 to 17 year. The study subjects, their parents, the nursing staff and the anesthesiologist and pediatrician involved in data collection or sedation and pain treatment were blinded to the type of insufflation used, but not the endoscopist to ensure proper technical performance. Sealed envelopes were opened by the endoscopist immediately before colonoscopy to switch on and off the $\mathrm{CO}_{2}$ regulation unit. All study data were registered anonymized on data sheets.

\section{Endoscopic procedure and $\mathrm{CO}_{2}$ insufflation}

Patients received a standardized full bowel cleansing according to age and body weight. Colonoscopies were performed by using small-caliber pediatric video-colonoscopes (Olympus EXERA series PCF-Q180, Germany) connected with a Xenon light source and an endoscopy video center (EVIS EXERA III CLV-190 and CV-190, Olympus, Germany). In some patients, depending on the indication, upper gastrointestinal endoscopy also was performed.

For $\mathrm{CO}_{2}$ insufflation, an endoscopic $\mathrm{CO}_{2}$ regulation unit (UCR Olympus, Germany) connected to a $\mathrm{CO}_{2}$ medical gas cylinder via a cylinder hose was used. The $\mathrm{CO}_{2}$ insufflator gas flow rate was controlled by a low flow gas tube (MAJ-1742, Olympus, Germany), connected with the water container (MAJ-902, Olympus, Germany). The manufacturer's data indicated a gas flow rate of $1.2 \mathrm{l} / \mathrm{min} \mathrm{CO}_{2}$ for the low-flow gas tube and $1.08 \mathrm{I}$ min room air via the light source CLV-190 using the pediatric colonoscope. Three experienced pediatric gastroenterologists and one trainee (not reached 50 endoscopies of the lower gas- trointestinal tract in children) performed the colonoscopies and the total procedure time was documented.

\section{Measurement of abdominal pain and assessment of abdominal discomfort}

Abdominal pain sensation in the patients before and after the procedure as the primary outcome measure was assessed by combining a 10-point visual analogue scale (VAS), numerical rating scales from 0 (no pain) to 10 points (maximal pain as worse as it could be), a colored analog scale and a face pain scale (scored 0, 2, 4, 6, 8, 10) ( Supplemental Table 1) appropriate for the study age group [14]. The participants were asked about pain 15 minutes before the examination and 15, 60, and 180 minutes and 24 hours afterwards. Necessity for pain-related analgetic usage was fixed in the health record of the patients. Abdominal discomfort was assessed post-procedure in a questionnaire by asking patients if they had abdominal pain (yes or no) and where. In addition, need for additional pain reliever was assessed and they were asked if they were bedridden (not at all, a little, or the whole day).

\section{Measurement of abdominal distension and assessment of bloating}

Abdominal girth at the navel was measured with a tape 5 minutes before and 5 and 60 minutes after the colonoscopy, indicating abdominal distension. Abdominal bloating was assessed post-procedure in a questionnaire by asking the patients if they felt mild or strongly bloated or not at all.

\section{Transcutaneous $\mathrm{pCO}_{2}$ measurement}

Transcutaneous $\mathrm{pCO}_{2}\left(\mathrm{p}_{\mathrm{TC}} \mathrm{CO}_{2}\right)$ was measured continuously with a noninvasive sensor (TCM TOSCA, Radiometer, Germany) attached to the ear lobe during the procedure. $\mathrm{P}_{\mathrm{TC}} \mathrm{CO}_{2}$ values were documented at particular times: at beginning of sedation, during colonoscopy (the highest and lowest) and afterwards. In addition, $\mathrm{P}_{\mathrm{TC}} \mathrm{CO}_{2}$ values were correlated with venous measured $\mathrm{pCO}_{2}$ in some patients to confirm reliability of the setting. The reliability of $\mathrm{p}_{\mathrm{TC}} \mathrm{CO}_{2}$ measurement was already demonstrated by others $[15,16]$. Oxygen saturation was measured by pulse oximetry.

\section{Registration of the narcotics}

Colonoscopies were performed in deeply sedated patients for optimal conditions during the examination. All patients were primarily sedated with midazolam and propofol by an anesthesiologist. In addition, further narcotics (alfentanil, remifentanil, ketamine) were used depending on patient need to achieve deep sedation and optimal examination conditions and prevent undesirable side effects caused by too high doses of propofol ( $4 \mathrm{mg} / \mathrm{kg}$ body weight per hour). The total dose of the narcotics $(\mathrm{mg} / \mathrm{kg}$ or $\mu \mathrm{g} / \mathrm{kg}$ ) was registered from the anesthetics protocol. Of note, the anesthesiologist was blinded in regard to the gas insufflated. 


\section{Study end points}

The primary end point of the study was assessment of patients' post-interventional pain sensation after 60 minutes. Secondary end points included post-interventional pain sensation after 15 and 180 minutes and 24 hours by VAS, subjective abdominal discomfort, objective abdominal distention, determined by abdominal circumference at the navel, the $\mathrm{pCO}_{2}$ levels assessed by transcutaneous measurement, total procedure time, and narcotic requirement to achieve deeply sedation and post-procedural analgesic demand.

\section{Statistical analysis}

Descriptive statistics were calculated for all categorical variables in absolute and relative frequencies. Continuous variables were analyzed by means of mean, standard deviation (SD), median, as well as minimum and maximum. Differences between $\mathrm{CO}_{2}$ and RA patients were assessed using the independent samples $t$-test in case of normally distributed variables and the Mann-Whitney-U test otherwise. Categorical variables were analyzed by means of the $x^{2}$ test or Fisher's exact test, respectively. The proportion of individuals reporting no pain on the VAS was exploratively compared at 15, 60, 180 minutes and 24 hours after intervention also using the $x^{2}$ or Fisher's exact test.

Adjunct criteria were defined as abdominal distension, duration of the examination, $\mathrm{pCO}_{2}$, and narcotic requirement. The graphical presentation is made as mean (+/-SD) as well as median value in Box \& Whisker plots. The level of statistical significance was set at $P<0.05$. All statistical analyses were performed using WinStat (Microsoft Excel by Koch Software).

\section{Sample size calculation and post-hoc power analysis}

We used the 2-sided $Z$ test for difference between two independent means (two groups). Based on previous adult studies, we assumed an effect size $d=0.67$ regarding pain reduction. A sample size of 36 subjects in each group achieved $80 \%$ power to detect significance $(\alpha=0.05)$. Post-hoc power analysis was performed on the basis of the mean values of the RA and $\mathrm{CO}_{2}$ group regarding pain reduction, abdominal discomfort and narcotic usage.

\section{Results}

A total of 260 colonoscopies were performed during the study period. Finally, 97 eligible children and adolescents agreed to participate and were randomized into $\mathrm{CO}_{2}$ or RA insufflation ( $\triangleright$ Fig.1). A total of 73 randomized patients with complete data sets were analyzed. The age of the $\mathrm{CO}_{2}$ group ranged between 4 and 17 years with a mean age of 13.7 years $( \pm 3.2)$ ( $\triangleright$ Table 1 ). The RA group was 7 to 17 years old with a mean age of $12.7( \pm 2.7) \cdot \mathrm{CO}_{2}$ was used for insufflation in 39 patients ( 22 male, 17 female) and RA in 34 patients ( 18 male, 16 female) ( Table 1).

Collectively, 44 patients (60.3\%) underwent colonoscopy because of an inflammatory bowel disease $\left(\mathrm{n}_{\mathrm{CO}_{2}}=26 / 66.7 \%\right.$; $\mathrm{n}_{\mathrm{RA}}=18 / 52.9 \%$ ). Other reasons were chronic abdominal pain, diarrhea, hematochezia, polyposis and constipation ( $\triangleright$ Table 1 ).

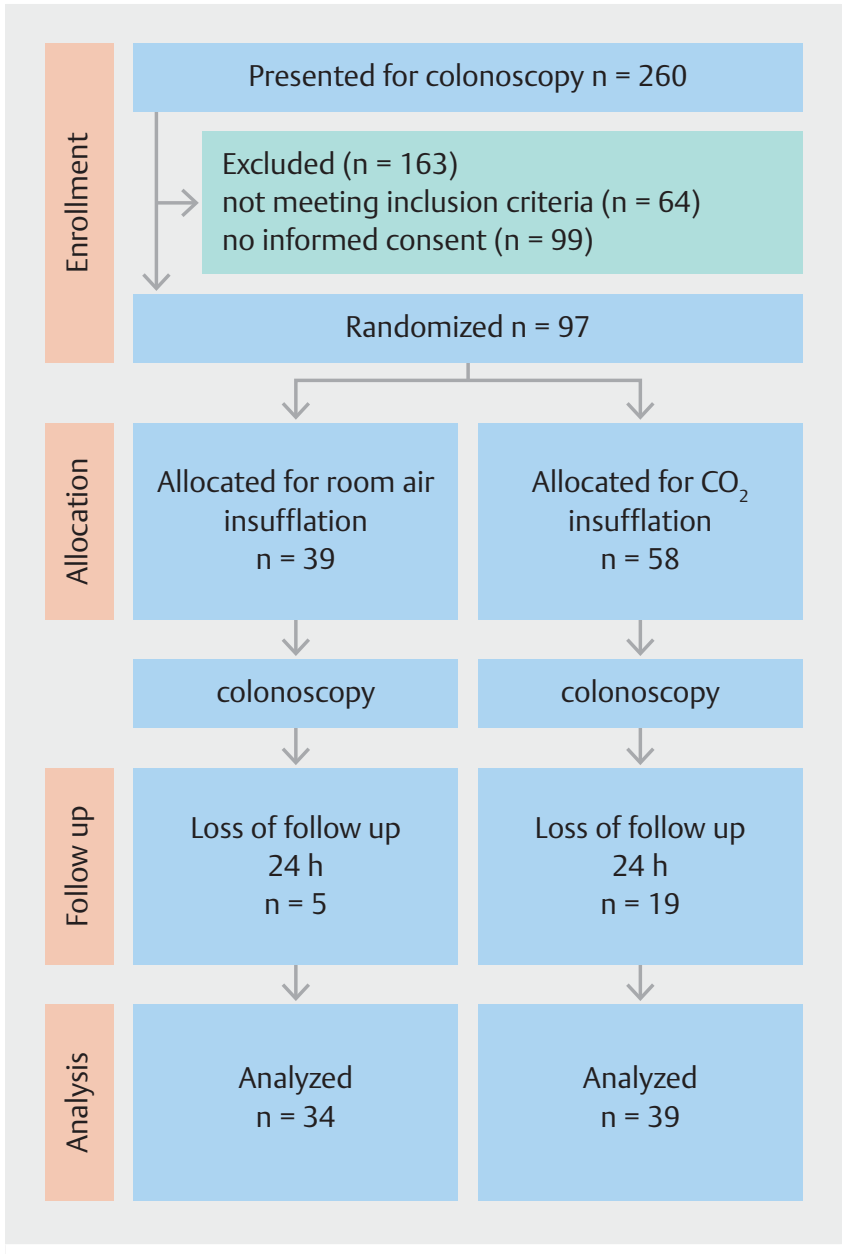

- Fig. 1 Study flow diagram.

Duration of colonoscopies varied between 15 and 120 minutes in both groups. Mean total procedure time was $31.3 \mathrm{~min}-$ utes $( \pm 13.2)$ in the $\mathrm{CO}_{2}$ group compared with 31.5 minutes $( \pm 16.7)$ in the RA group $(P>0.94$ not significant, $>$ Table 1$)$. Colonoscopy duration was comparable in both age groups (children 4-12 years: mean $32.3 \mathrm{~min}(\mathrm{SD} \pm 13.4 \mathrm{~min})$ vs. teenagers: mean $30.9 \mathrm{~min}(S \mathrm{~S} \pm 16.2 \mathrm{~min})$ ). The three experienced pediatric endoscopists performed 65 (89\%) of the colonoscopies and mean total procedure time among them ranged from 27.8 minutes to 37.3 minutes compared to 42.6 minutes for the trainee ( $\triangleright$ Supplemental Fig. 1 ).

No interventional adverse event occurred in any patient.

Baseline characteristics were similar across the study groups ( $\downarrow$ Table 1 ). In spite of randomization, there are approximately two homologous examination groups.

\section{Effect of $\mathrm{CO}_{2}$ insufflation on post-procedural abdominal pain}

A total of 30 patients undergoing colonoscopy experienced pain, of whom 13 received $\mathrm{CO}_{2}$ (33.3\%) and $17 \mathrm{RA}(50 \%)(P=$ 0.15) ( Table 1). In addition, VAS scores for pain were lower in the $\mathrm{CO}_{2}$ group compared to the RA group at all time points (15 and 60 minutes as well as 3 and 24 hours) after the exami- 
- Table 1 Patient and procedure characteristics in the $\mathrm{CO}_{2}$ and room air groups.

\begin{tabular}{|c|c|c|c|}
\hline & $\begin{array}{l}\mathrm{CO}_{2} \text { insufflation } \\
\mathrm{N}=39\end{array}$ & $\begin{array}{l}\mathrm{RA} \text { insufflation } \\
\mathrm{N}=34\end{array}$ & $\begin{array}{l}P \text { value } \\
\mathrm{X}^{2} \text { or } t \text {-test }\end{array}$ \\
\hline Mean age, years (mean $\pm S D$; range) & $13.7 \pm 3.2(4-17)$ & $12.7 \pm 2.7(7-17)$ & $0.15^{2}$ \\
\hline Female $(\mathrm{n}, \%)$ & $17(43.6)$ & $16(47.1)$ & $0.77^{1}$ \\
\hline Weight, kg (mean \pm SD) & $50.2 \pm 15.5$ & $46.8 \pm 12.5$ & $0.31^{2}$ \\
\hline Body mass index (mean $\pm S D$ ) & $19.5 \pm 3.5$ & $19.0 \pm 2.5$ & $0.47^{2}$ \\
\hline Upper gastrointestinal endoscopy [n (\%)] & $22(56.4)$ & $21(61.8)$ & $0.64^{1}$ \\
\hline \multicolumn{4}{|l|}{ Indications [n (\%)] } \\
\hline - Inflammatory Bowel Disease & $25(64.1)$ & $19(55.8)$ & $0.23^{1}$ \\
\hline - Active disease & $12(30.8)$ & $11(32.4)$ & \multirow[t]{2}{*}{$0.52^{1}$} \\
\hline - Evaluation of therapy effectiveness & $13(33.3)$ & $8(23.5)$ & \\
\hline - Chronic abdominal pain & $5(12.8)$ & $8(24.2)$ & $0.23^{1}$ \\
\hline - Diarrhea & $2(5.1)$ & $2(5.8)$ & $0.89^{1}$ \\
\hline - Hematochezia & $4(10.2)$ & $2(5.8)$ & $0.5^{1}$ \\
\hline - Others & $3(7.7)$ & $3(8.8)$ & $0.86^{1}$ \\
\hline Abdominal pain ( $\mathrm{n}(\%))$ & $13(33,3)$ & $17(50)$ & $0.15^{1}$ \\
\hline \multicolumn{4}{|l|}{ Abdominal bloating ( $\mathrm{n}(\%))$} \\
\hline None & $27(69.2)$ & $10(29.4)$ & \multirow[t]{3}{*}{$0.0012^{1}$} \\
\hline Mild & $11(28.2)$ & $17(50)$ & \\
\hline Strong & $1(2.6)$ & $7(20.5)$ & \\
\hline \multicolumn{4}{|l|}{ Medication for deep sedation } \\
\hline propofol mg/kg (mean; range) & $5.68(0.25-15.0)$ & $5.69(2.8-13.9)$ & n.s. \\
\hline Additional narcotic usage (n;(\%)) & $16(43.5)$ & $23(67.6)$ & $0.023^{1}$ \\
\hline Total examination time, min (mean $\pm S D)$ & $31,3 \pm 13,2$ & $31,5 \pm 16,7$ & $0.94^{2}$ \\
\hline $\begin{array}{l}\mathrm{CO}_{2} \text {, carbon dioxide; } \mathrm{RA} \text {, room air } \\
{ }^{1} \text { by Chi-square test (or Fisher's exact test) for } \\
{ }^{2} \text { t-test. }\end{array}$ & & & \\
\hline
\end{tabular}

nation ( $\triangleright$ Fig. 2). If the mean pain score is set to $100 \%$ at the time point of 60 minutes after the intervention with RA, the mean value of the $\mathrm{CO}_{2}$ group is $80 \%$. However, these differences reached not significance.

Irrespective of the insufflated gas, maximum pain was noticed 60 minutes after the examination and pain decreased continuously thereafter in both groups. The $\mathrm{CO}_{2}$ group showed a wide range of pain intensity post-procedure at 60 minutes, although the majority of this group declared no pain compared to the RA arm $(P=0.27)$.

Only one patient undergoing colonoscopy with $\mathrm{CO}_{2}$ insufflation needed analgesics after the procedure due to abdominal pain. No participant declared pain that hampered him from getting out of bed.

\section{Effect of $\mathrm{CO}_{2}$ insufflation on abdominal distension and bloating}

Patients receiving $\mathrm{CO}_{2}$ reported significantly less bloating in comparison with patients in the RA group $(P=0.0012)(\nabla \mathrm{Ta}$ ble 1 ). Twenty-seven patients (69.2\%) undergoing colonoscopy with $\mathrm{CO}_{2}$ insufflation reported no bloating compared to $10 \mathrm{pa}$ tients $(29.4 \%)$ receiving $R A$ insufflation.

In addition, the differences between the abdominal girth before and 5 or 60 minutes after colonoscopy were compared. Five minutes after the examination the mean difference was $2.8 \mathrm{~cm}( \pm 1.5)$ in the $\mathrm{CO}_{2}$ group and $2.7 \mathrm{~cm}( \pm 2.1)$ in the $\mathrm{RA}$ group ( $P=0.59$ ) ( Supplemental Fig. 2). Accordingly, 60 minutes after colonoscopy there was no significant difference in abdominal girth, $1.2 \mathrm{~cm}( \pm 1.2)$ in the $\mathrm{CO}_{2}$ group versus $1.6 \mathrm{~cm}$ $( \pm 1.5)$ in the RA group $(P=0.4)$ ( $\triangleright$ Supplemental Fig. 3 ). 


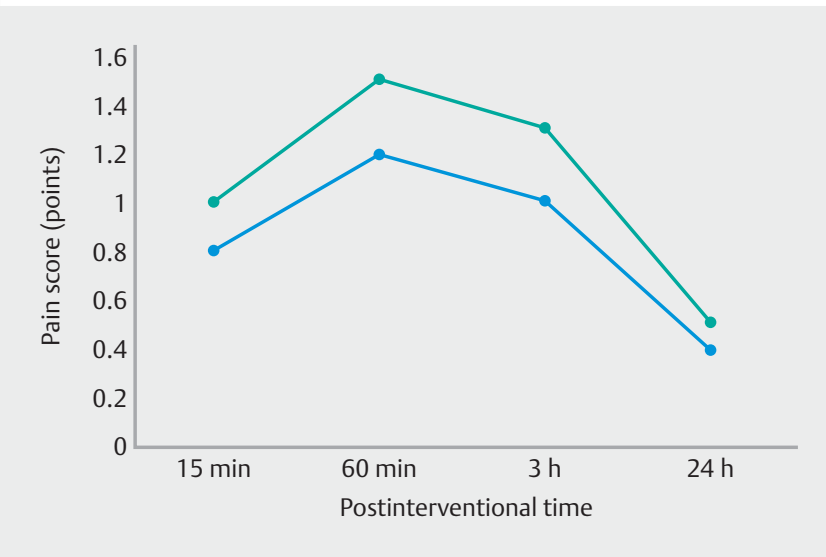

- Fig. 2 Interventional-related pain sensation. Mean values for pain assessed by an age-appropriate combination of a 10-point visual analogue scale (VAS) $(0=$ no pain, $10=$ maximum imaginable pain), a numerical rating scale, a colored analog scale and a face pain scale at the time points 15 minutes, 60 minutes, 3 hours and 24 hours after colonoscopy according to type of gas are indicated (mean carbon dioxide group (blue), mean room air group (green).

\section{Influence of $\mathrm{CO}_{2}$-insufflation on transcutaneous $\mathrm{pCO}_{2}$}

Transcutaneous $\mathrm{pCO}_{2}(\mathrm{mmHg})$ was continuously measured in all patients before, during and after the examination. The highest values of the $\mathrm{P}_{\mathrm{TC}} \mathrm{CO}_{2}$ during the examination varied between 30 and $61 \mathrm{mmHg}$ in the $\mathrm{CO}_{2}$ group with a median of $44 \mathrm{mmHg}$ compared to $42.5 \mathrm{mmHg}$ in the RA group $(P=0.27)$. Of note, that high value only happened once in the $\mathrm{CO}_{2}$ group. The maximum $\mathrm{P}_{\mathrm{TC}} \mathrm{CO}_{2}$ mean value during the colonoscopy in the $\mathrm{CO}_{2}$ group was $44.8 \mathrm{~mm} \mathrm{Hg}( \pm 7.3)$ in comparison to $42.6 \mathrm{~mm} \mathrm{Hg}$ $( \pm 4.7)$ in the RA group ( $\bullet$ Fig. 3 ). There was no significant difference in $\mathrm{P}_{\mathrm{TC}} \mathrm{CO}_{2}$ levels between the groups before, during and after the procedure.

\section{Narcotic usage during the procedure}

All but one patient received propofol for sedation. The mean dosage of propofol and midazolam were similar in both study groups (propofol $5.7 \mathrm{mg} / \mathrm{kg}$, midazolam $0.08 \mathrm{mg} / \mathrm{kg}$ per examination) and independent of the indication ( $\vee$ Supplemental Fig.3). Subject to the patient, further narcotics such as alfentanyl, remifentanil, and ketamine were used to achieve optimal examination conditions. Sixteen patients $(43.5 \%)$ in the $\mathrm{CO}_{2}$ group and $23(67.6 \%)$ in the RA group needed additional narcotics $(P=0.023)(\triangleright$ Table 1$)$.

\section{Post-hoc power analysis}

Post-hoc power analysis revealed a power of less than $10 \%$ for post-procedural abdominal pain assessments by VAS after 60 minutes (primary endpoint) and 180 minutes and less than $30 \%$ for abdominal pain at all. The post-hoc power analysis for abdominal bloating was $98 \%$ and additional narcotic usage $52 \%$.

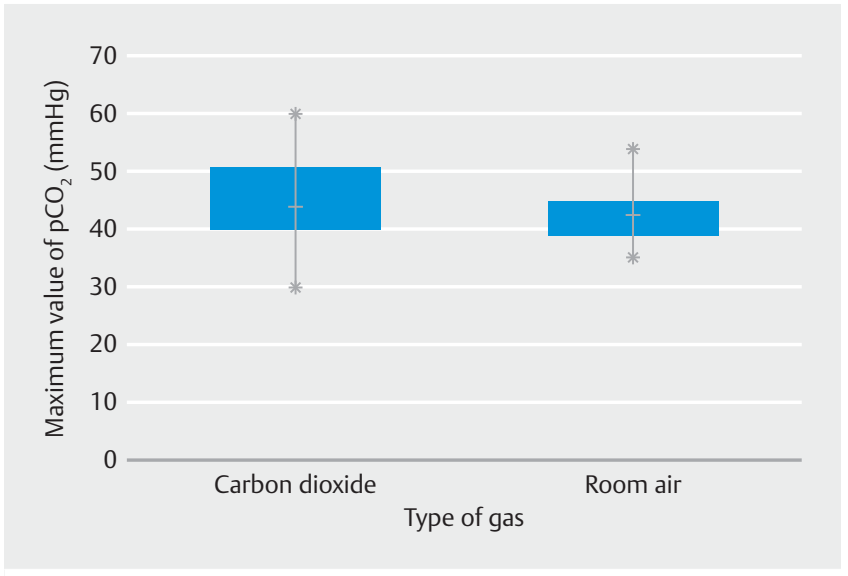

- Fig. 3 Maximum $\mathrm{p}_{\mathrm{TC}} \mathrm{CO}_{2}$ values during examination. Box and whisker plots of the maximum value of the $\mathrm{P}_{\mathrm{TC}} \mathrm{CO}_{2}$ (in $\mathrm{mmHg}$ ) during the examination, separated into the different types of gas. The whiskers indicate the $5 \%$ and $95 \%$ quantile (x), the median is symbolized by a -, the maximum or the minimum by $\mathrm{a}+(P=0.27)$.

\section{Discussion}

We performed a prospective RCT comparing $\mathrm{CO}_{2}$ versus $\mathrm{RA}$ insufflation during colonoscopy to investigate post-procedural pain, abdominal discomfort and distension, narcotic requirement and $\mathrm{pCO}_{2}$ retention in deeply sedated pediatric patients. This study may be biased as the endoscopists were not blinded to randomization.

Overall fewer patients reported abdominal pain by trend and significantly fewer patients felt bloated in the $\mathrm{CO}_{2}$ group. However, this was reflected only by a slightly lower post-interventional pain score, documented at 1, 3 and 24 hours, and it did not reach significance. Already, several RCTs in adults have reported a reduction in pain after colonoscopy with $\mathrm{CO}_{2}$ insufflation, either significant or by trend $[1-5,7,9,10,17]$. Reduction in pain was observed at between 1 and 6 hours after examination [6]. This is in line with our observation and that of another pediatric $\mathrm{RCT}$ investigating $\mathrm{CO}_{2}$ versus $\mathrm{RA}$ insufflation in slightly older patients with very similar patient characteristics [18]. Interestingly, we observed much lower pain scores using an ageappropriate combination of a 10-point VAS, a numerical rating scale, a colored analog scale and a face pain scale than reported with assessment of abdominal pain using a numeric pain scale (NRS-11) [18]. Of note, in our study, considerably fewer patients received upper gastrointestinal endoscopies (58\% versus $80 \%$ ) and children older than age 3 years were included in contrast to those older than age 6 years in the other pediatric study. In addition, different sedation protocols were used that may also influence absolute pain scores. As a result, our effect size was lower than expected and accordingly our sample size was underrated as shown by our post-hoc power analysis regarding the primary endpoint of post-procedural abdominal pain reduction.

Abdominal bloating was significantly reduced using $\mathrm{CO}_{2}$ insufflation instead of RA in the current study. This was also re- 
flected in studies in adults. However, the comparability is somehow limited as measurement of bloating was different $[9,19]$. Mostly, flatulence was explored using questionnaires with different scales of points [4] compared to others using abdominal radiography to measure distension of bowel lumen in adults [1,2]. Interestingly, in almost three-quarters of patients receiving $R A$, colon diameter was still over $6 \mathrm{~cm} 1$ hour after the procedure compared to $4 \%$ of those examined with carbon dioxide [2]. Here we used abdominal girth at the navel to detect abdominal distension due to over-distended bowel and observed a significantly faster decrease in abdominal circumference in the carbon dioxide group than in the RA group 1 hour after the procedure. However, surprisingly this difference was not significant. Similarly, this was also reported in the pediatric study by Homan et al. and suggests that measuring abdominal circumference is not an accurate method to assess over-distended bowel [18]. However, exposure to radiation for a more accurate measurement is not justified in children and will not be approved by the Federal Office for Radiation Protection.

Although there was no difference in dosage of propofol and midazolam, we observed a significant increased necessity for additional synthetic opioid use in the RA group compared to the carbon dioxide group to achieve optimal examination conditions independent of the indication. This may reflect a more painful examination during the colonoscopy using RA compared to carbon dioxide and is supported by a study showing lesser request for on-demand sedation in adults starting colonoscopy without premedication using carbon dioxide [20]. In addition, lesser demand for sedation is reported in adults undergoing advanced endoscopic procedures e.g. double-balloon enteroscopy or colorectal submucosal dissections using $\mathrm{CO}_{2}$ [21, 22]. Furthermore, additional opioid use may also diminish reported post-procedural abdominal pain in these patients as these drugs are still effective after the examination. Thus, lower differences observed in the VAS between both groups at 1 and 3 hours in our study may be a result of analgesic effects of these synthetic opioids. Therefore, assessment of the smaller effect of $\mathrm{CO}_{2}$ insufflation on VAS in our study should take into account that adults received less opioids for endoscopy in these studies $[4,16,21-24]$ and sedation of children in the other pediatric study was based on a combination of ketamine and midazolam.

This is the first pediatric study monitoring $\mathrm{pCO}_{2}$ during colonoscopy. Of note, no pathological increase in transcutaneous $\mathrm{pCO}_{2}$ was reported leading to a discontinuation of the investigation. Although the maximum $\mathrm{pCO}_{2}$ value in the carbon dioxide group was higher than in the RA group (61 versus 54 $\mathrm{mmHg}$ ) on average, there was no significant difference between the groups in maximum $\mathrm{pCO}_{2}$ levels. Hence, carbon dioxide insufflation for endoscopy in children is as safe as in adults.

\section{Conclusion}

In conclusion, the benefits of using carbon dioxide during colonoscopy of deeply sedated children predominate. In particular, $\mathrm{CO}_{2}$ insufflation reduces abdominal bloating significantly and may allow a less painful post-interventional time in children. In this study of deeply sedated children, pain score assessed by
VAS in children receiving RA was already considerably lower than in other studies and minimized the effect on post-interventional pain reduction in the $\mathrm{CO}_{2}$ group. However, significantly fewer synthetic opioids were used during colonoscopy using carbon dioxide, indicating a less painful examination. In addition, carbon dioxide insufflation can be considered as safe in deeply sedated pediatric patients as there was no relevant pulmonary $\mathrm{CO}_{2}$ retention observed. In this respect, carbon dioxide instead of RA can be recommended for endoscopy in children. Further pediatric RCTs are needed to verify the impact of $\mathrm{CO}_{2}$ insufflation on pain perception.

\section{Acknowledgements}

We thank all patients and their families for participation in this study. We thank our colleagues Claudia Graßhof and Kirsten Lang for patient enrollment and performing colonoscopies in this study.

\section{Competing interests}

None

\section{References}

[1] Stevenson GW, Wilson JA, Wilkinson J et al. Pain following colonoscopy: elimination with carbon dioxide. Gastrointest Endosc 1992; 38: $564-567$

[2] Sumanac K, Zealley I, Fox BM et al. Minimizing postcolonoscopy abdominal pain by using $\mathrm{CO}$ insufflation: A prospective, randomized, double blind, controlled trial evaluating a new commercially available CO delivery system. Gastrointest Endosc 2002; 56: 190 - 194

[3] Bretthauer M, Hoff GS, Thiis-Evensen E et al. Air and carbon dioxide volumes insufflated during colonoscopy. Gastrointest Endosc 2003; 58: $203-206$

[4] Geyer M, Guller U, Beglinger C. Carbon dioxide insufflation in routine colonoscopy is safe and more comfortable: results of a randomized controlled double-blinded trial. Diagn Ther Endosc 2011; 2011: 378906

[5] Hussein AM, Bartram Cl, Williams CB. Carbon dioxide insufflation for more comfortable colonoscopy. Gastrointest Endosc 1984; 30: 68 70

[6] Yamano HO, Yoshikawa K, Kimura T et al. Carbon dioxide insufflation for colonoscopy: evaluation of gas volume, abdominal pain, examination time and transcutaneous partial $\mathrm{CO}_{2}$ pressure. J Gastroenterol 2010; 45: $1235-1240$

[7] Yasumasa K, Nakajima K, Endo S et al. Carbon dioxide insufflation attenuates parietal blood flow obstruction in distended colon: potential advantages of carbon dioxide insufflated colonoscopy. Surg Endosc 2006; 20: $587-594$

[8] Bretthauer M, Lynge AB, Thiis-Evensen E et al. Carbon dioxide insufflation in colonoscopy: safe and effective in sedated patients. Endoscopy 2005; 37: $706-709$

[9] Dellon ES, Hawk JS, Grimm IS et al. The use of carbon dioxide for insufflation during $\mathrm{Gl}$ endoscopy: a systematic review. Gastrointest Endosc 2009; 69: 843-849

[10] Sajid MS, Caswell J, Bhatti MI et al. Carbon dioxide insufflation vs conventional air insufflation for colonoscopy: a systematic review and 
meta-analysis of published randomized controlled trials. Colorectal Dis 2015; 17: $111-123$

[11] Wang WL, Wu ZH, Sun Q et al. Meta-analysis: the use of carbon dioxide insufflation vs. room air insufflation for gastrointestinal endoscopy. Aliment Pharmacol Ther 2012; 35: 1145-1154

[12] Memon MA, Memon B, Yunus RM et al. Carbon dioxide versus air insufflation for elective colonoscopy: a meta-analysis and systematic review of randomized controlled trials. Surg Laparosc Endosc Percu$\tan$ Tech 2016; 26: $102-116$

[13] World Medical. World Medical Association Declaration of Helsinki: ethical principles for medical research involving human subjects. JAMA 2013; 310: 2191 -2194

[14] von Baeyer CL. Children's self-reports of pain intensity: Scale selection, limitations and interpretation. Pain Res Manage 2006; 11: 157 162

[15] Kikuchi T, Fu KI, Saito Y et al. Transcutaneous monitoring of partial pressure of carbon dioxide during endoscopic submucosal dissection of early colorectal neoplasia with carbon dioxide insufflation: a prospective study. Surg Endosc 2010; 24: 2231-2235

[16] Nonaka S, Saito Y, Takisawa $\mathrm{H}$ et al. Safety of carbon dioxide insufflation for upper gastrointestinal tract endoscopic treatment of patients under deep sedation. Surg Endosc 2010; 24: 1638-1645

[17] Bretthauer M, Thiis-Evensen E, Huppertz-Hauss G et al. NORCCAP (Norwegian colorectal cancer prevention): a randomised trial to assess the safety and efficacy of carbon dioxide versus air insufflation in colonoscopy. Gut 2002; 50: 604-607
[18] Homan M, Mahkovic D, Orel R et al. Randomized, double-blind trial of $\mathrm{CO}_{2}$ versus air insufflation in children undergoing colonoscopy. Gastrointest Endosc 2016; 83: 993 - 997

[19] Wu J, Hu B. The role of carbon dioxide insufflation in colonoscopy: a systematic review and meta-analysis. Endoscopy 2012; 44: 128-136

[20] Amato A, Radaelli F, Paggi S et al. Carbon dioxide insufflation or warm-water infusion versus standard air insufflation for unsedated colonoscopy: a randomized controlled trial. Dis Colon Rectum 2013; 56: $511-518$

[21] Domagk D, Bretthauer M, Lenz P et al. Carbon dioxide insufflation improves intubation depth in double-balloon enteroscopy: a randomized, controlled, double-blind trial. Endoscopy 2007; 39: 1064 1067

[22] Saito Y, Uraoka T, Matsuda T et al. A pilot study to assess the safety and efficacy of carbon dioxide insufflation during colorectal endoscopic submucosal dissection with the patient under conscious sedation. Gastrointest Endosc 2007; 65: 537- 542

[23] Heuss LT, Sugandha SP, Beglinger C. Carbon dioxide accumulation during analgosedated colonoscopy: comparison of propofol and midazolam. World J Gastroenterol 2012; 18: 5389-5396

[24] Riss S, Akan B, Mikola B et al. $\mathrm{CO}_{2}$ insufflation during colonoscopy decreases post-interventional pain in deeply sedated patients: a randomized controlled trial. Wiener klinische Wochenschrift 2009; 121: $464-468$ 
- Supplemental Table 1 Influence of the endoscopist on pain scale and mean total procedure time

\begin{tabular}{|c|c|c|c|c|c|c|}
\hline Endoscopist & & 1 & 2 & 3 & Trainee & TOTAL \\
\hline \multirow[t]{3}{*}{ Number of colonoscopies } & $\mathrm{CO}_{2}$ & 9 & 3 & 21 & 6 & 39 \\
\hline & Room air & 7 & 5 & 20 & 2 & 34 \\
\hline & Total & $16[21,9 \%]$ & 8 [11\%] & $41[56,2 \%]$ & $8[11 \%]$ & 73 \\
\hline \multirow[t]{3}{*}{ Pain scale after 60 minutes (mean) } & $\mathrm{CO}_{2}$ & 1,6 & 2,3 & 2,0 & 1,8 & 1,9 \\
\hline & Room air & 3,6 & 4,2 & 2,6 & 0 & 2,9 \\
\hline & Total & 2,4 & 3,5 & 2,3 & 1,4 & 2,3 \\
\hline \multirow[t]{3}{*}{ Mean total procedure time (min) } & $\mathrm{CO}_{2}$ & 27,8 & 32,0 & 28,0 & 48,5 & 31,4 \\
\hline & Room air & 27,9 & 40,4 & 30,8 & 25,0 & 31,3 \\
\hline & Total & 27,8 & 37,3 & 29,4 & 42,6 & 31,3 \\
\hline
\end{tabular}

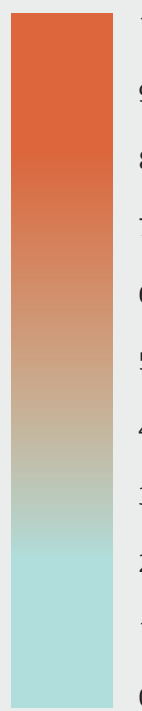

\begin{tabular}{ll}
10 & Maximal pain \\
9 & \\
8 & \\
7 & \\
6 & \\
5 & \\
4 & \\
3 & \\
2 & \\
1 & Normal pain \\
0 & \\
\hline
\end{tabular}

- Supplemental Fig. 1 Visual analogue scale (VAS). We used a 10-point visual analogue scale combining numerical rating scales from zero (=no pain) to ten points (maximal pain as worse as it could be), a colored analog scale from blue to red and a face pain scale (scored $0,2,4,6,8,10$ ) to quantify age appropriate pain perception.
10

8

6

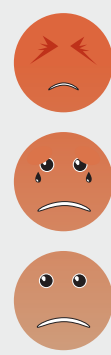

4

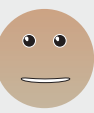

2

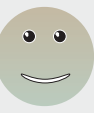

0

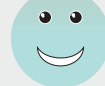

